\title{
O TARIFAMENTO DO DANO MORAL TRABALHISTA NA PERSPECTIVA DO PRINCÍPIO DA IGUALDADE
}

\section{Max Emiliano da Silva Sena ${ }^{1}$}

\section{RESUMO}

Este artigo propõe-se a pesquisar resposta à seguinte indagação: o tarifamento do dano moral trabalhista introduzido pela Lei $\mathrm{n}^{\circ}$ 13.467/2017 viola a igualdade constitucional? Adotou-se como marco teórico a perspectiva de Celso Antônio Bandeira de Mello acerca do conteúdo jurídico do princípio da igualdade. A importância do tema ressai dos debates atuais acerca da utilização do valor do salário do trabalhador para a fixação da referida indenização. Utilizouse o método de abordagem dedutivo e a pesquisa dogmático-jurídica de natureza bibliográfica, com a consulta de obras e legislação.

PALAVRAS-CHAVE: Constituição de 1988; Dignidade da pessoa humana; Princípio da igualdade; Tarifamento do dano moral trabalhista; Valor social do trabalho.

\section{THE PRICE OF LABOR MORAL DAMAGE FROM THE PERSPECTIVE OF THE PRINCIPLE OF EQUALITY}

\begin{abstract}
This article proposes to search for an answer to the following question: does the tariff for labor moral damage introduced by Law No. 13,467 / 2017 violate constitutional equality? Celso Antônio Bandeira de Mello's perspective on the legal content of the principle of equality was adopted as a theoretical framework. The importance of the theme comes from the current debates about the use of the value of the worker's salary to fix the referred compensation. The deductive approach method and the dogmatic-legal research of bibliographic nature were used, with the consultation of works and legislation.
\end{abstract}

KEYWORDS: Constitution of 1988; Dignity of human person; Equality principle; Tariff for labor moral damage; Social value of labor.

\section{INTRODUÇÃO}

Fundado na necessidade do estabelecimento de critérios objetivos, ante a constatação de vácuo legislativo, e no crescimento do ajuizamento de ações de reparação na Justiça do Trabalho, o legislador infraconstitucional brasileiro introduziu dispositivos normativos na Consolidação das Leis do Trabalho (CLT), por meio da Lei ${ }^{\circ} 13.467 / 2017$, fixando limites

\footnotetext{
${ }^{1}$ Doutorando em Direito pela PUC-MINAS. Mestre em Direito pela Universidade FUMEC. Procurador do Trabalho (MPT). Especialista em Direitos Humanos e Trabalho pela ESMPU e em Direito Público pela FADIVALE. Professor de Direito Constitucional da FADIVALE. E-mail: emilianosena@ hotmail.com. Endereço: Rua Prudente de Morais, 660, Centro, Governador Valadares-MG, CEP 35.20-460.
} 
para o valor da indenização por dano moral exclusivamente decorrente das relações de trabalho.

Além de estabelecer os marcos legislativos para o dano moral trabalhista, deixando de fora todas as demais relações jurídicas, o legislador fixou os parâmetros da indenização com base no valor do salário contratual do empregado ofendido.

O tema problema da presente pesquisa consiste na seguinte indagação: o tarifamento do dano moral trabalhista introduzido pela Lei $\mathrm{n}^{\circ} 13.467 / 2017$ viola o princípio da igualdade? Adotou-se como marco teórico a perspectiva de Celso Antônio Bandeira de Mello acerca do conteúdo jurídico do princípio da igualdade, especificamente o critério para análise de eventual violação da isonomia, consubstanciado na correlação lógica da norma com os interesses absorvidos no sistema constitucional e por ele juridicizados.

O presente artigo encontra-se dividido em seis capítulos, incluído este capítulo primeiro, destinado à introdução. No capítulo segundo serão feitas considerações legislativas sobre a fixação do tarifamento da indenização do dano moral trabalhista. O capítulo terceiro dedicar-se-á a analisar os parâmetros de fixação da indenização com base no valor do salário do trabalhador. No capítulo quarto será feito estudo a respeito do princípio da igualdade e dos critérios para análise de sua eventual violação à luz dos elementos teóricos de autoria de Celso Antônio Bandeira de Mello. Após o estudo dos elementos teóricos básicos referentes ao tema, no capítulo quinto proceder-se-á ao exame de conformação entre o tarifamento do dano moral e o princípio da igualdade. Finalmente, no capítulo sexto serão tecidas as considerações finais acerca do estudo realizado.

Para o alcance do objetivo proposto utilizou-se o método de abordagem indutivo e a pesquisa dogmático-jurídica de natureza bibliográfica, por meio da consulta de obras e legislação.

\section{CONSIDERAÇÕES LEGISLATIVAS SOBRE O TARIFAMENTO DO DANO MORAL TRABALHISTA}

A Lei $n^{\circ} 13.467 / 2017$, conhecida como lei da reforma trabalhista, estabeleceu regramento aplicável à reparação do dano extrapatrimonial decorrente das relações de trabalho, por meio da introdução do Título II-A na Consolidação das Leis do Trabalho (CLT), denominado "Do dano extrapatrimonial" e integrado pelos artigos 223-A a 223-G. 
No que diz respeito ao tema problema desta pesquisa, tem-se que no artigo 223-G, $\S 1^{\circ}$, da CLT, o legislador infraconstitucional, por meio da referida Lei $n^{\circ} 13.467 / 2017$, estabeleceu os limites dos valores em caso de eventual indenização pela prática de dano extrapatrimonial, impondo ao juiz a observância dos seguintes parâmetros:

\footnotetext{
"I - ofensa de natureza leve, até três vezes o último salário contratual do ofendido;

II - ofensa de natureza média, até cinco vezes o último salário contratual do ofendido;

III - ofensa de natureza grave, até vinte vezes o último salário contratual do ofendido;

IV - ofensa de natureza gravíssima, até cinquenta vezes o último salário contratual do ofendido." (BRASIL, 1943).
}

A inovação legal, portanto, leva em consideração a natureza da ofensa (leve, média, grave ou gravíssima) e o valor do salário contratual do ofendido, para que o juiz fixe a condenação pecuniária a ser paga pelo ofensor em favor da vítima do dano moral decorrente das relações de trabalho. Se o ofendido for pessoa jurídica, o valor da indenização observará igualmente os parâmetros estabelecidos pela lei, tomando como base o salário contratual do ofensor.

De acordo com a lei em análise, os regramentos que fixam limites ao valor do dano extrapatrimonial aplicam-se apenas à reparação de danos dessa natureza que sejam decorrentes de relação de trabalho, ou seja, às outras relações jurídicas não podem ser opostas as limitações então estabelecidas.

Os bens jurídicos passíveis de proteção pela nova lei e ínsitos à pessoa física são: a honra, a imagem, a intimidade, a liberdade de ação, a autoestima, a sexualidade, a saúde, o lazer e a integridade física. Quanto à pessoa jurídica, os bens tutelados são os seguintes: a imagem, a marca, o nome, o segredo empresarial e o sigilo da correspondência (BRASIL, 1943).

Ao juiz cabe observar os seguintes parâmetros no caso de acolhimento do pedido de indenização por dano extrapatrimonial trabalhista: a) natureza do bem jurídico cuja tutela se pleiteia; b) intensidade do sofrimento ou humilhação impingidos à vítima; c) possibilidade de superação física ou psicológica do dano; d) reflexos pessoais e sociais da conduta omissiva ou comissiva; e) extensão e duração dos efeitos da ofensa; f) condições em que ocorreu a ofensa ou prejuízo moral; g) grau de dolo ou culpa; h) ocorrência ou não de retratação espontânea do ofensor; i) esforço efetivo do ofensor para minimizar a ofensa; j) perdão, tático ou expresso; 
k) situação social e econômica das partes envolvidas; e 1) grau de publicidade da ofensa. (BRASIL, 1943).

A discussão objeto da presente pesquisa reside especificamente na análise da fixação do valor da indenização por dano extrapatrimonial com base no valor do salário contratual do trabalhador ofendido, notadamente se esse critério encontra-se em sintonia com o princípio da igualdade, constitucionalmente previsto. Isso porque, conforme previsto na própria lei, outras relações jurídicas, que não decorram do vínculo de emprego entre o empregador e o empregado, ficam de fora do regramento introduzido na CLT pela Lei $\mathrm{n}^{\circ}$ 13.467/2017.

\section{PARÂMETROS DE FIXAÇÃO DA INDENIZAÇÃO COM BASE DO VALOR DO SALÁRIO DO TRABALHADOR}

Os motivos que levaram ao estabelecimento de limites para o valor da indenização por dano extrapatrimonial podem ser extraídos da análise do parecer ao projeto de lei da reforma trabalhista, materializada na Lei $\mathrm{n}^{\circ} 13.467 / 2017$, que introduziu o artigo 223-G na Consolidação das Leis do Trabalho, para tratar especificamente do tema.

No referido parecer, a Comissão Especial da Câmara dos Deputados ponderou que dia após o dia vem crescendo o ajuizamento de ações, requerendo a indenização por danos morais, além do dano existencial. Apesar da previsão constitucional da reparação do dano moral, a Comissão Especial manifestou a sua discordância com a falta de critério na fixação dos valores da condenação. (BRASIL, 2017a).

A Comissão Especial da Câmara dos Deputados aduziu que, em razão da inexistência de previsão expressa nas leis trabalhistas de critérios para a fixação do valor da condenação, os pedidos de reparação dos danos morais são formulados com base na legislação civil, que igualmente não oferece critérios objetivos a respeito da matéria (BRASIL, 2017a).

$\mathrm{Na}$ opinião da Comissão Especial, são comuns indenizações que desconsideram a capacidade econômica do ofensor (empregado ou empregador), o que acabaria por agravar a situação em desfavor dos empregadores, uma vez que ações de prepostos podem levar à condenação da empresa ao pagamento de indenização em valores que dificultam ou até mesmo inviabilizam a continuidade do negócio (BRASIL, 2017a).

A par dessa motivação fática, fundamentadora da inovação legislativa, tem-se que o artigo 223-G, $\S 1^{\circ}$, da CLT, estabelece limites para o valor da indenização por dano 
extrapatrimonial, os quais levam em consideração o valor do salário contratual do ofendido e a gravidade da ofensa.

Nesse sentido, o valor da condenação pela prática de dano moral extrapatrimonial trabalhista será diretamente proporcional ao valor do salário contratual do ofendido, de modo que quanto maior for o salário da vítima maior poderá ser o valor da indenização.

Entende-se que a eleição de critérios é relevante para a fixação do valor das indenizações em geral, não somente daquelas decorrentes das relações de trabalho. Mas o que se intenta investigar neste artigo é se à luz do princípio da igualdade, constitucionalmente previsto, o estabelecimento do valor do salário contratual do trabalhador se revela adequado para tanto.

A par disso, passar-se-á nos próximos capítulos a analisar os requisitos ínsitos ao princípio da igualdade, para se lançar as bases teóricas para o confronto entre o tarifamento do valor do dano moral e o referido princípio, especificamente para se promover um exame de conformidade entre a norma legal e o princípio constitucional.

\section{O PRINCÍPIO DA IGUALdADE E OS CRITÉRIOS PARA ANÁLISE DE SUA VIOLAÇÃO}

Se é verdade que ainda hoje as pessoas não desfrutam da igualdade real no patamar desejável, também é verdade que nem sempre as leis lhes conferiram, ainda que formalmente, tratamento equilibrado e igualitário.

$\mathrm{Na}$ gestação histórica ocidental dos direitos humanos, os primeiros direitos traduziram limitações impostas ao Estado e aos governantes em geral, como forma de proteger os indivíduos dos abusos outrora perpetrados sob a égide dos regimes absolutistas. Esses direitos, chamados de primeira dimensão, podem ser exemplificados no direito à vida, à propriedade, à participação política, à liberdade e à igualdade.

Nesse sentido, a Declaração Universal dos Direitos Humanos, da Organização das Nações Unidas, datada de 10 de dezembro de 1948, estabelece em seu artigo 1': "Todos os seres humanos nascem livres e iguais em dignidade e em direitos. Dotados de razão e de consciência, devem agir uns para com os outros em espírito de fraternidade." (ORGANIZAÇÃO, 1948). 
Inspirada na Declaração Universal dos Direitos Humanos e em vários outros documentos internacionais que elevam a igualdade como princípio a ser observado em favor de todos os seres humanos, a Constituição da República Federativa do Brasil, de 1988, em seu artigo $5^{\circ}$, caput, estabelece: “Todos são iguais perante a lei, sem distinção de qualquer natureza, garantindo-se aos brasileiros e aos estrangeiros residentes no País a inviolabilidade do direito à vida, à liberdade, à igualdade, à segurança e à propriedade [...]”. (BRASIL, 1988).

Embora o dispositivo acima referido limite-se, a princípio, à igualdade formal, ou seja, de todos perante a lei, José Afonso da Silva registra que a Constituição de 1988 "reforça o princípio com muitas outras normas sobre a igualdade ou buscando a igualização dos desiguais pela outorga de direitos substanciais." (SILVA, 2008, p. 211).

Com efeito, o compromisso da Constituição de 1988 com a igualdade substancial pode ser constatado por meio dos vários direitos sociais conferidos aos trabalhadores no artigo $7^{\circ}$ e nos objetivos eleitos como razão de ser e de existir da República Federativa do Brasil, previstos no artigo $3^{\circ}$, valendo destacar o seu inciso III: "erradicar a pobreza e a marginalização e reduzir as desigualdades sociais e regionais.” (BRASIL, 1988).

A finalidade da igualdade formal, de todos perante a lei, é coibir tratamentos privilegiados e desarrazoados entre pessoas que se encontram na mesma situação jurídica. A igualdade substancial, por seu turno, objetiva compensar as desigualdades reais e fáticas, por meio de ações afirmativas em favor de pessoas hipossuficientes, para a concretização da justiça social (SENA; BARBOSA, 2018).

A respeito da justiça concreta ou material, José Afonso da Silva aduz que seria:

“[...] a especificação da justiça formal, indicando a característica constitutiva da categoria essencial, chegando-se às formas: a cada um segundo a sua necessidade; a cada um segundo seus méritos; a cada um a mesma coisa. Porque existem desigualdades, é que se se aspira à igualdade real ou material que busque realizar a igualização das condições desiguais [...]”' (SILVA, 2008, p. 213-214).

O princípio da igualdade dirige-se a todos, indistintamente, por força das eficácias vertical e horizontal dos direitos fundamentais, ou seja, mediante sua oposição ao Estado e aos particulares, respectivamente.

Todavia, de forma bastante contundente, o legislador é um dos principais destinatários do princípio da igualdade, na medida em que por meio dos regramentos normativos é que poderão aflorar desigualdades desarrazoadas, odiosas e, portanto, inconstitucionais. 
A propósito, Celso Antônio Bandeira de Mello assenta o seguinte a respeito do princípio da igualdade: "Entende-se, em concorde unanimidade, que o alcance do princípio não se restringe a nivelar os cidadãos diante da norma legal posta, mas que a própria lei não pode ser editada em desconformidade com a isonomia" (MELLO, 2017, p. 9).

Além de sua oposição primordialmente ao Estado, o princípio da igualdade traduz comando a ser observado também pelos particulares em suas relações jurídicas, por força da eficácia horizontal dos direitos fundamentais (SARMENTO, 2006).

A respeito do estudo sobre os princípios, Robert Alexy destaca que: “os princípios são normas que ordenam que algo seja realizado na maior medida possível dentro das possibilidades jurídicas e fáticas existentes.”(ALEXY, 2017, p. 90).

Aplicando-se tais lições teóricas à presente exposição, tem-se que o princípio da igualdade consubstancia norma de natureza constitucional, portanto, de nível hierárquico superior no ordenamento jurídico, que ordena que o seu conteúdo seja concretizado da forma mais ampla e profunda possível, no âmbito das possibilidades jurídicas e fáticas vivenciadas em determinado momento.

Não obstante, não é incomum a ocorrência de entrechoques entre princípios constitucionais, o que reclama do intérprete esforço no sentido de se utilizar das ferramentas hermenêuticas disponíveis para tentar compatibilizar os interesses ou sopesá-los e definir qual deles, na situação específica e concreta posta, deverá prevalecer em relação ao outro.

Portanto, em situações de entrechoques entre o princípio da igualdade e outros princípios constitucionais, é possível aplicar tais bases teóricas para, na situação concreta, verificar qual princípio deve prevalecer.

Adotou-se como marco teórico desta pesquisa o entendimento de Celso Antônio Bandeira de Melo acerca do conteúdo jurídico do princípio da igualdade. A partir do estudo da teoria formulada sobre o tema pelo referido autor, será possível proceder à análise de conformidade entre o tarifamento do dano moral trabalhista sob estudo e o princípio constitucional da igualdade.

Mário Lúcio Quintão Soares discorre sobre a teoria de John Locke a respeito da gestação do Estado, aduzindo que: "compreende igualdade como a situação onde a reciprocidade determina todo o poder e toda a competência, mas não é estado de permissividade em que os homens podem pilhar uns os outros.” (SOARES, 2011, p. 59). 
A igualdade objetiva, nessa linha teórica de John Locke, estabelecer bloqueio à opressão estatal em face do indivíduo ou de um particular em relação ao outro, o que pode ser analisado à luz dos abusos praticados pelos governantes na égide dos regimes absolutistas e, também, mais recentemente na história, por força das explorações praticadas por um poder econômico descompromissado com valores humanitários.

Os movimentos constitucionalistas resultaram na previsão de direitos em favor dos indivíduos nas constituições, como forma de proteger as pessoas de abusos, com eficácia tanto vertical quanto horizontal, ou seja, em face do Estado e também dos particulares.

Todavia, como analisado no início deste capítulo, em que pesem as previsões de igualdade nos textos das constituições, é comum a ocorrência de entrechoques entre princípios constitucionais, de maneira que, em relação ao princípio da igualdade especificamente, faz-se necessário investigar o seu conteúdo jurídico, para melhor análise da questão.

Isso porque, historicamente, o que se observa é que as desigualdades são reais e comuns, não sendo passíveis de solução por simples previsões normativas. O que se veda não é o tratamento desigual em si, mas, sim, o tratamento desigual fundado em motivos desarrazoados e inadequados.

Oposto a todos e principalmente ao legislador, tem-se que a lei não pode e não deve ser fonte de privilégio e nem tampouco de perseguições, mas mecanismo de regulação da vida em sociedade, mediante tratamento equitativo e parificado de todos os cidadãos. Segundo Celso Antônio Bandeira de Mello, "esse é o conteúdo político-ideológico absorvido pelo princípio da isonomia e juridicizado pelos textos constitucionais em geral, ou de todo modo assimilado pelos sistemas normativas vigentes.” (MELLO, 2017, p. 10).

Vedam-se tratamentos diversos para pessoas que se encontram em situações equivalentes. Encontrando-se as pessoas em situações equivalentes, devem receber tratamento igual, sem privilégios ou perseguições.

Há critérios aptos à identificação do desrespeito à isonomia, segundo Celso Antônio Bandeira de Mello:

\footnotetext{
"Parece-nos que o reconhecimento das diferenciações que não podem ser feitas sem quebra da isonomia se divide em três questões: a) a primeira diz com o elemento tomado como fator de desigualação; b) a segunda reporta-se à correlação lógica abstrata existente entre o fato erigido em critério de discrímen e a disparidade estabelecida no tratamento jurídico diversificado; c) a terceira atina à consonância desta correlação lógica com os interesses absorvidos no sistema constitucional e destarte juridicizados.” (MELLO, 2017, p. 21).
} 
Para a análise do tema problema proposto nesta pesquisa, destaca-se o terceiro critério descrito por Celso Antônio Bandeira de Mello, referente à consonância ou à conformação da correlação lógica entre o fato erigido em critério de discrímen com os interesses absorvidos no sistema constitucional e por ele juridicizados.

Esse exame de conformidade ocorre mediante a análise sistêmica da Constituição de 1988, por meio da verificação de compatibilidade do motivo eleito como critério de discriminação com os demais valores juridicizados na forma de princípios constitucionais.

O critério de conformação lógica exige do intérprete uma análise substancial da constituição, haja vista que, na esteira de Celso Antônio Bandeira de Mello: "É possível obedecer-se formalmente um mandamento, mas contrariá-lo em substância. Cumpre verificar se foi atendida não apenas a letra do preceito isonômico, mas também seu espírito [...]" (MELLO, 2017, p. 24).

No próximo capítulo, dedicar-se-á especificamente ao cotejamento entre o tarifamento do dano moral e o princípio da igualdade, a par do seu conteúdo jurídico, a fim de se verificar a sua adequação constitucional ou mesmo a existência de eventual conflito entre valores constitucionalmente tutelados.

\section{O TARIFAMENTO DO DANO MORAL E O PRINCÍPIO DA IGUALDADE}

$\mathrm{Na}$ esteira da teoria construída por Celso Antônio Bandeira de Mello sobre o conteúdo jurídico do princípio da igualdade, especificamente no que tange aos critérios para se investigar eventual violação do referido princípio em situações de entrechoques normativos, tem-se a verificação da consonância da correlação lógica de uma determinada norma com os interesses absorvidos no sistema constitucional e por ele juridicizados.

Nenhum direito, regra ou princípio deve ser analisado de forma isolada e sim de forma sistemática, levando em consideração a totalidade do ordenamento jurídico posto. No âmbito das normas constitucionais não é diferente.

Nesse sentido, o princípio da igualdade encontra-se conectado a vários outros princípios constitucionais, notadamente com o princípio da dignidade da pessoa humana, previsto no artigo $1^{\circ}$, inciso II, como fundamento da República Federativa do Brasil (BRASIL, 1988).

A depender do bem jurídico envolvido, outros princípios poderão ser manejados para uma análise mais consentânea com as finalidades sociais pretendidas pelo Constituinte 
originário, as quais são de observância obrigatória pelo legislador infraconstitucional, pelos intérpretes e por todos os aplicadores da norma.

Considerando que o tema dessa exposição tangencia relação de trabalho, notadamente a indenização por dano decorrente dessa espécie de relação jurídica, outros princípios devem ser aplicados na investigação de resposta ao tema problema proposto, consistente na seguinte indagação: O tarifamento do dano moral trabalhista introduzido pela Lei ${ }^{\circ} 13.467 / 2017$ viola o princípio da igualdade?

Assim, além da dignidade da pessoa humana, possuem correlação com o tema os princípios do valor social do trabalho, da função social da propriedade, da prevalência dos direitos humanos e da justiça social, todos com assento constitucional.

O tarifamento do valor de indenização por dano extrapatrimonial, exclusivamente aplicável às relações de trabalho, atende a uma demanda empresarial, no sentido de estabelecer limites para a fixação de indenizações deferidas pelo Judiciário trabalhista, pautando-se, assim, no princípio constitucional da livre iniciativa.

Segundo Cármen Lúcia Antunes Rocha,

Igualdade constitucional é mais que uma expressão de Direito; é um modo justo de se viver em sociedade. Por isso é princípio posto como pilar de sustentação e estrela de direção interpretativa das normas jurídicas que compõem o sistema jurídico fundamental." (ROCHA, 1990, p. 118).

Segundo Ana Paula de Barcellos, a revisitação da história informa que na segunda metade do século XX as constituições transformaram-se no “[...] repositório jurídico de valores compartilhados pela sociedade sob a forma de opções políticas fundamentais e de programas de ação vinculantes para os poderes públicos.” (BARCELLOS, 2011, p. 23).

A Constituição de 1988 não é axiologicamente neutra, antes, pelo contrário, representa o repositório de valores entendidos como de maior relevância para a vida em sociedade, por meio de um processo democrático que conduziu à sua construção e promulgação.

Entre os valores eleitos, tem-se o valor igualdade, jurididizado e materializado no princípio da igualdade, que permeia todo o texto constitucional, tanto no aspecto da igualdade formal quanto no aspecto da igualdade substancial.

Nessa perspectiva de igualdade material ou substancial, o artigo $3^{\circ}$ da Constituição estabelece os objetivos da República, valendo destacar as ações para erradicar a pobreza e a marginalização e para reduzir as desigualdades sociais e regionais, conforme inciso III (BRASIL, 1988). 
Na concretização desse objetivo o trabalho, como fator de desenvolvimento, possui um relevante papel, na medida em que, segundo Max Emiliano da Silva Sena:

\footnotetext{
Na Constituição de 1988 (CR/88), o trabalho deve gerar desenvolvimento para o trabalhador, passo a passo com o crescimento econômico. Esse desenvolvimento liga-se à promoção da liberdade, da igualdade e da dignidade em favor do indivíduo por meio do trabalho." (SENA, 2019, p. 134)
}

Essa previsão atende à necessidade de promover a proteção da pessoa humana, figura central do ordenamento jurídico brasileiro, dos males do mercado, haja vista que historicamente condutas econômicas despidas de eticidade acabaram por reduzir o trabalho e o trabalhador a meros fatores de produção (GRAU, 2017; SENA, 2019).

É possível, assim, a defesa de que a Constituição de 1988 conferiu ao trabalho importante função para a concretização da igualdade substancial, a começar pela elevação do valor social do trabalho ao patamar de fundamento da República Federativa do Brasil, conforme artigo $1^{\circ}$, IV, da Constituição, e da previsão de vários direitos trabalhistas no seu artigo $7^{\circ}$ (BRASIL, 1988).

Além disso, o constituinte originário assentou no artigo 170, da CR/88, que a ordem econômica não é um fim si mesma, devendo fundar-se na valorização do trabalho humano e na livre iniciativa e assegurar a todos a existência digna, em padrões de justiça social (BRASIL, 1988).

José Afonso da Silva entende que, na Constituição brasileira de 1988, a ordem econômica os valores humanos desfrutam de preferência em relação a todos os outros valores de mercado (SILVA, 2008).

As opções axiológicas positivadas na Constituinte vigente, portanto, assentam o necessário respeito ao trabalho em condições de dignidade e à garantia de sua função enquanto fator de desenvolvimento pessoal e social.

A par dessas considerações, apreciadas à luz do critério de análise de eventual violação do princípio da igualdade, teorizado por Celso Antônio Bandeira de Mello, consistente na verificação da consonância da correlação lógica de uma determinada norma com os interesses absorvidos no sistema constitucional e por ele juridicizados, tem-se que o trabalho digno e a sua consideração enquanto fator de desenvolvimento integram o núcleo essencial da Constituição de 1988. 
Assentadas tais bases teóricas, é possível proceder à verificação de conformação da inovação legislativa introduzida na Consolidação das Leis do Trabalho (CLT) quanto ao tarifamento da indenização do dano moral trabalhista.

Com efeito, a Lei $\mathrm{n}^{\mathrm{o}} 13.467 / 2017$ introduziu na CLT o artigo 223-G, §1 , estabelecendo os limites dos valores em caso de eventual indenização pela prática de dano extrapatrimonial, impondo ao juiz a observância de parâmetros.

A inovação legal leva em consideração a natureza da ofensa (leve, média, grave ou gravíssima) e o valor do salário contratual do ofendido, para que o juiz proceda à fixação do valor da condenação pecuniária a ser paga pelo ofensor em favor da vítima do dano moral decorrente das relações de trabalho.

A fixação dos referidos limites, segundo restou estabelecido, aplica-se somente às indenizações por danos decorrentes das relações de trabalho, de modo que outras relações jurídicas ficaram de fora do alcance dos marcos fixados.

O status de empregado, na espécie, está a significar que o valor de indenização terá um limite de acordo com o valor do salário contratual do trabalhador.

É possível extrair pelo menos dois descompassos em relação ao princípio da igualdade levados a efeito pela regra prevista no $223-\mathrm{G}, \S 1^{\circ}$, da CLT, utilizando o critério da correlação lógica da norma com os interesses absorvidos no sistema constitucional e por ele juridicizados.

O trabalho recebeu relevante destaque pela Constituição de 1988, cujo valor social foi alçado à condição preemiente de fundamento da República Federativa do Brasil. Além dessa condição, a ordem econômica deve pautar-se na valorização do trabalho humano e ter como objetivo assegurar a todos existência digna e gerar justiça social.

Dessa forma, a relação de trabalho não pode significar fator de diminuição de direitos ou um patamar de inferiorização do empregado no que tange ao usufruto de bens jurídicos assegurados pelo ordenamento jurídico.

No caso em estudo, a fixação de limites ao valor da indenização por danos morais introduzida pela Lei n ${ }^{\circ}$ 13.467/2017 aplica-se somente às relações de trabalho, de modo que a condição de empregado significa uma inferiorização da vítima de dano moral em relação as outras pessoas ofendidas, cujos danos não tenham sido decorrentes de uma relação trabalhista.

Um segundo descompasso com o princípio da igualdade reside na fixação do valor da indenização levando-se em consideração o valor contratual do salário do empregado, o que 
está a significar que, quanto maior for o salário do indivíduo, maior poderá ser o valor da indenização a ser fixada pelo juiz.

Esse critério fundado no valor contratual do salário importa em desarrazoada discriminação em desfavor do empregado que recebe um salário menor, o que não se encontra em consonância com o princípio da igualdade, além de malferir da mesma forma os princípios da dignidade da pessoa humana e do valor social do trabalho.

A métrica da quantia pecuniária referente ao salário contratual recebido pelo trabalhador vai na contramão do refinado espírito humanista preconizado por Immanuel Kant a respeito do valor intrínseco ao ser humano, consistente na sua dignidade, o que em muito difere de preço de uma contraprestação (KANT, 2011).

A dor moral de uma pessoa não será maior ou mais relevante do que a de outra em razão da quantia pecuniária do salário recebido, a ponto de quem ganha mais obter uma reparação extrapatrimonial maior.

Na linha de Pablo Stolze Gagliano e Rodolfo Pamplona Filho, "o dano moral consiste na lesão de direitos, cujo conteúdo não é pecuniário, nem comercialmente redutível a dinheiro.” (GAGLIANO; PAMPLONA FILHO, 2018, p. 932). A lesão ocorre na esfera personalíssima da pessoa, violando direitos que integram o seu patrimônio moral, como a intimidade, a honra, a imagem e outros de natureza imaterial.

A reparação extrapatrimonial, também denominada indenização, pelos danos morais praticados possui com objetivo minimizar a dor moral, por meio de uma compensação pecuniária em favor do ofendido ou de sua família, de modo que não se mostra adequada aquilatar a dor moral a partir do valor do salário contratual do trabalhador.

As diferenciações introduzidas pela Lei $\mathrm{n}^{\circ}$ 13.467/2017 revelam-se, assim, desarrazoadas, na medida em que considera o empregado um ser humano de segunda categoria em relação àqueles que não ostentem a condição de empregado ou não estejam sob a égide de uma relação de emprego no momento da ocorrência do dano.

Isso porque não haverá tarifação na indenização eventualmente deferida para os não empregados ou empregados que não estiverem trabalhando no momento do dano, pois a limitação aplica-se somente à indenização por dano ocorrido numa relação de emprego.

De acordo com Celso Antônio Bandeira de Mello,

Para que um discrímen legal seja convivente com a isonomia, consoante visto até agora, impende que concorram quatro elementos: [...] d) que, in concreto, o vínculo de correlação suprarreferido seja pertinente em função dos interesses 
constitucionalmente protegidos, isto é, resulte em diferenciação de tratamento jurídico fundado em razão valiosa - ao lume do texto constitucional - para o bem público." (MELLO, 2017, p. 41).

O mesmo autor acima consiga que: "Reversamente, não podem ser colocadas em desvantagem pela lei situações a que o sistema constitucional empresta conotação positiva." (MELLO, 2017, p. 42).

No artigo $7^{\circ}$, caput, da Constituição de 1988 , o constituinte originário introduziu o princípio da melhor condição em favor do trabalhador, vez que, antes de enumerar vários direitos sociais trabalhistas, deixou consignado que, além deles, outros poderão ser acrescidos, desde que visassem à melhoria da condição social do trabalhador.

O patamar fixado na CLT pela Lei $n^{\circ} 13.467 / 2017$, com o tarifamento do dano moral decorrente da relação de empregado, não se coaduna com o princípio da igualdade por colocar o empregado em situação de desvantagem no sistema constitucional que prestigia os direitos decorrentes das relações de trabalho e impõe a valorização do trabalho humano.

Em arremate, Celso Antônio Bandeiro de Mello defende que: "a lei não pode atribuir efeitos valorativos, ou depreciativos, a critério especificador, em desconformidade ou contradição com os valores transfundidos no sistema constitucional ou nos padrões éticosociais acolhidos neste ordenamento." (MELLO, 2017, p. 42).

Assim, a partir dos critérios que fundamentam a análise do conteúdo jurídico do princípio da igualdade, observa-se a ausência de conformação entre a Constituição de 1988 e o tarifamento da indenização do moral decorrente das relações de trabalho, na medida em os limites estabelecidos não encontram correlação lógica com os interesses absorvidos no sistema constitucional e por ele juridicizados e aplicáveis às relações de trabalho.

\section{CONSIDERAÇÕES FINAIS}

A Lei $n^{\circ} 13.467 / 2017$ estabeleceu regramento aplicável exclusivamente à reparação do dano extrapatrimonial decorrente das relações de trabalho, por meio da introdução do Título II-A na Consolidação das Leis do Trabalho (CLT), denominado "Do dano extrapatrimonial" e integrado pelos artigos 223-A a 223-G.

A inovação legal leva em consideração a natureza da ofensa (leve, média, grave ou gravíssima) e o valor do salário contratual do ofendido, para que o juiz fixe a condenação 
pecuniária a ser paga pelo ofensor em favor da vítima do dano moral decorrente das relações de trabalho. Se o ofendido for pessoa jurídica, o valor da indenização observará igualmente os parâmetros estabelecidos pela lei, tomando como base o salário contratual do ofensor.

O tema problema proposto consistiu na indagação acerca da compatibilidade do tarifamento da indenização dano moral trabalhista com o princípio da igualdade, diante da aplicação do regramento exclusivamente às relações de trabalho e à consideração do valor do salário contratual do empregado como parâmetro para a fixação do valor da indenização.

A par do marco teórico adotado, consubstanciado no critério descrito por Celso Antônio Bandeira de Mello, referente à consonância ou à conformação da correlação lógica entre o fato erigido em critério de discrímen com os interesses absorvidos no sistema constitucional e por ele juridicizados, é possível extrair pelo menos dois descompassos em relação ao princípio da igualdade levados a efeito pela regra prevista no $223-\mathrm{G}, \S 1^{\circ}$, da CLT.

No tange à primeira desconformidade, tem-se que o trabalho recebeu relevante destaque pela Constituição de 1988, cujo valor social foi alçado à condição preemiente de fundamento da República Federativa do Brasil. Além dessa condição, a ordem econômica deve pautar-se na valorização do trabalho humano e ter como objetivo assegurar a todos existência digna e gerar justiça social.

Dessa forma, a relação de trabalho não pode significar fator de diminuição de direitos ou um patamar de inferiorização do empregado no que tange ao usufruto de bens jurídicos assegurados pelo ordenamento jurídico.

No caso em estudo, a fixação de limites ao valor da indenização por danos morais introduzida pela Lei no 13.467/2017 aplica-se somente às relações de trabalho, de modo que a condição de empregado significa uma inferiorização da vítima de dano moral em relação as outras pessoas ofendidas, cujos danos não tenham sido decorrentes de uma relação trabalhista.

Um segundo descompasso com o princípio da igualdade reside na fixação do valor da indenização levando-se em consideração o valor contratual do salário do empregado, o que está a significar que, quanto maior for o salário do indivíduo, maior poderá ser o valor da indenização a ser fixada pelo juiz.

Esse critério fundado no valor contratual do salário importa em desarrazoada discriminação em desfavor do empregado que recebe um salário menor, o que não se encontra em consonância com o princípio da igualdade, além de malferir igualmente os princípios da dignidade da pessoa humana e do valor social do trabalho. 
As diferenciações introduzidas pela Lei $\mathrm{n}^{\circ}$ 13.467/2017 revelam-se, assim, desarrazoadas, na medida em que considera o empregado um ser humano de segunda categoria em relação àqueles que não ostentem a condição de empregado ou não estejam sob a égide de uma relação de emprego no momento da ocorrência do dano.

Assim, a partir dos critérios que fundamentam a análise do conteúdo jurídico do princípio da igualdade, observa-se a ausência de conformação entre a Constituição de 1988 e o tarifamento da indenização do moral decorrente das relações de trabalho, na medida em os limites estabelecidos não encontram correlação lógica com os interesses absorvidos no sistema constitucional e por ele juridicizados e aplicáveis às relações de trabalho.

\section{REFERÊNCIAS}

ALEXY, Robert. Teoria dos direitos fundamentais. Tradução de Virgílio Afonso da Silva. 2.ed. São Paulo: Malheiros, 2017.

BARCELLOS, Ana Paula de. A eficácia jurídica dos princípios constitucionais: o princípio da dignidade da pessoa humana. 3.ed. revista e atualizada. Rio de Janeiro: Renovar, 2011.

BRASIL. Lei Federal no 13.467, de 13 de julho de 2017. Disponível em:

<http://www.planalto.gov.br/ccivil_03/_ato2015-2018/2017/lei/113467.htm>. Acesso em: 18 abr.2020.

BRASIL. Câmara dos Deputados. Relatório da Comissão Especial destinada a proferir parecer ao projeto de lei $\mathrm{n}^{\mathrm{o}}$ 6787, de 2016, do Poder Executivo, que altera o Decreto-lei $\mathrm{n}^{\circ}$ 5452, de $1^{\circ}$ de maio de 1943 - Consolidação das Leis do Trabalho. Ano de 2017. Acesso em: 01 fev.2020. Disponível em:

https://www.camara.leg.br/proposicoesWeb/prop_mostrarintegra?codteor=1544961.

BRASIL. Constituição da República Federativa do Brasil (1988). Disponível em: http://www.planalto.gov.br/ccivil_03/constituicao/ConstituicaoCompilado.htm. Acesso em: 01 fev.2020.

BRASIL. Decreto-lei $n^{0}$ 5.452, de $1^{\circ}$ de maio de 1943. Consolidação das Leis do Trabalho. Disponível em: <https://www.planalto.gov.br/ccivil_03/Decreto-

Lei/Del5452compilado.htm>. Acesso em: 01 fev.2020.

GAGLIANO, Pablo Stolze; PAMPLONA FILHO, Rodolfo. Manual de Direito Civil.

Volume único. 2. ed. São Paulo: Saraiva, 2018.

GRAU, Eros Roberto. A ordem econômica na Constituição de 1988: interpretação e crítica. 18.ed. São Paulo: Malheiros, 2017. 
KANT, Immanuel. Fundamentação da metafísica dos costumes e outros escritos.

Tradução de Leopoldo Holzbach. São Paulo: Martin Claret, 2011.

MELLO, Celso Antônio Bandeira de. O conteúdo jurídico do princípio da igualdade. 3.ed. Rio de Janeiro: Malheiros, 2017.

NEVES DELGADO, Gabriela. Direito fundamental ao trabalho digno. 2.ed. São Paulo: Ltr, 2015.

ORGANIZAÇÃO das Nações Unidas. Declaração Universal dos Direitos Humanos, de 10 de dezembro de 1948. Disponível em: <http://

http://www.ohchr.org/EN/UDHR/Documents/UDHR_Translations/por.pdf >. Acesso em: 02 abr.2020.

ROCHA, Cármen Lúcia Antunes. O princípio constitucional da igualdade. Belo Horizonte: Lê, 1990.

SENA, Max Emiliano da Silva; BARBOSA, Liliane Lisboa de Oliveira.

Direitos humanos e ações afirmativas no direito brasileiro: contribuição da teoria liberal de John Rawls. In: Revista de Direitos Humanos e Efetividade Salvador, BA: 2018, v. 4, n. 1, jan/jun 2018, p. 21-41. Disponível em: <

https://www.indexlaw.org/index.php/revistadhe/article/view/4013/pdf>. Acesso em: 01 maio.2020.

SENA, Max Emiliano da Silva. A força normativa do valor social do trabalho. Rio de Janeiro: Lumen Juris, 2019.

SILVA, José Afonso da. Curso de direito constitucional positivo. 30.ed. São Paulo: Malheiros, 2008.

SOARES, Mário Lúcio Quintão. Teoria do estado: novos paradigmas em face da globalização. 4.ed. revista e ampliada. São Paulo: Atlas, 2011. 